\section{La educación virtual en la Facultad de Ciencias Ambientales de la UTP y su aporte a la sustentabilidad.}

Carlos Ignacio Jiménez Montoya ${ }^{1}$, Andrés Felipe Muñoz Ramírez y Jorge Alberto Lozano Valencia

${ }^{1}$ Universidad Tecnológica de Pereira, Colombia carlosignaciojimenez@utp.edu.co

\section{Virtual education in the Faculty of Environmental Sciences of the UTP and its contribution to sustainability.}

Recibido: $12 / 12 / 2017$

Aceptado: $20 / 04 / 2018$

Publicado: $29 / 06 / 2018$

\title{
RESUMEN
}

El presente trabajo tiene como propósito indagar en el imaginario colectivo que sobre temas ambientales poseen los estudiantes del campus universitario de la Universidad Tecnológica de Pereira, con el fin de incluir la dimensión ambiental en el quehacer de los profesionales que se forman al interior de esa institución. Para el cumplimiento del objetivo propuesto se plantea la complementariedad etnográfica como propuesta metodológica para consolidar la información. Una vez recopilados, analizados y aprobados en la práctica reflexiva los datos, se establece aquel y se consolida una cátedra virtual denominada «Producción y consumo sustentable», que se oferta como asignatura electiva para todos los programas académicos, logrando incorporar así la dimensión ambiental en todos los campos de formación profesional.

PALABRAS CLAVE: ambiente, comunidad universitaria, imaginarios.

\section{ABSTRACT}

The purpose of this work is to investigate the collective imaginary that environmental students have on the campus of the Technological University of Pereira on environmental issues, in order to include the environmental dimension in the work of the professionals who are trained inside that institution. In order to fulfill the proposed objective, ethnographic complementarities is proposed as a methodological proposal to consolidate the information. Once the data is collected, analyzed and approved in reflective practice, it is established and a virtual chair called "Sustainable production and consumption" is established, which is offered as an elective subject for all academic programs, thus incorporating the environmental dimension into All fields of professional training.

KEYWORDS: environment, imaginary, university community.

\section{INTRODUCCIÓN}

Los seres humanos desde sus múltiples relaciones van representando la realidad que les circunda en imágenes que, al ser cargadas de sentido, conforman el mundo de lo imaginario o pregnancia simbólica a decir Cassirer (1971). Según Peñuela y Álvarez los imaginarios son:

... mundos posibles en los cuales se mueven y desenvuelven los sujetos, son configuraciones de las imágenes que la cultura le ha dejado como huella y la forma como 
ellos mismos recrean una y otra vez aquella. Nos representamos en el otro, nos identificamos con él, queremos conocerlo, aprehenderlo, robarle su imagen. (2002, párr.3)

El paso de lo imaginario a lo simbólico es el verdadero ejercicio de opinión y análisis. Siempre será una construcción individual objetivada en el consenso colectivo pues depende, en gran medida, de los imaginarios que se tengan como individuo o grupo social; es por ello que toda acción encaminada a cambiar los modos de actuación de una persona o sociedad debe estar ligada a sus imaginarios, de lo contrario, dichas acciones pasarán desapercibidas o con muy poco o bajo impacto.

Trabajar con esta dimensión, o sea, lo imaginario en los salones de clases, comunidad y prácticas de sensibilización en educación ambiental o pedagógico ambientales, partiendo de los imaginarios colectivos ambientales presentes; de la estimulación de la capacidad creativa de los sujetos en formación sin que ello signifique la pérdida de importancia del conocimiento científico, es de suma importancia en la actualidad como lo es la interpenetración de los saberes y la extracción de su interdependencia con los objetos propios de la praxis educativa.

Si se planteasen las preguntas ¿cuáles son los imaginarios colectivos ambientales que presenta la comunidad educativa de la Universidad Tecnológica de Pereira (UTP) y de qué forma estos pueden optimizar los alcances de su práctica pedagógica ambiental?, la respuesta obtenida serviría entonces como punto de partida de todo proceso con referente pedagógico ambiental en la universidad, lo cual impactaría significativamente en los resultados esperados de cada proceso.

Por tanto, el presente trabajo pretende evidenciar los imaginarios colectivos ambientales existentes al interior del campus de la UTP, con el fin de incluir dicha temática en la práctica profesional de los educandos, a través de la implementación de una cátedra electiva denominada Producción y consumo sustentable.

Finalmente, el documento generado servirá para generar reflexiones no solo desde el quehacer docente, sino desde la extensión misma que la universidad promueve, con el firme propósito de alcanzar sus planteamientos misionales.

\section{Algunos referentes necesarios}

Comprender la interacción del ser humano con su entorno representa un incentivo para investigar sobre su percepción ambiental. En este sentido, ella ha sido estudiada mediante conceptos propios del medio ambiente o desde referencias a fenómenos y problemas ambientales, pero esos aspectos conceptuales de extrema importancia en los referidos estudios, representan sólo un punto en la complejidad que caracteriza al fenómeno perceptivo. De esta forma, si se enfocan las prácticas educativas en él, se estará también orientándolas hacia el carácter informacional, basado en la transmisión de información científica sobre los fenómenos y los componentes del medio natural. (Marin, Torres y Comar, 2003)

Sobre esa temática, Lefft afirma:

La cuestión ambiental, más que una problemática ecológica, es una crisis del pensamiento y del entendimiento, de la ontología y de la epistemología con las que la civilización occidental ha comprendido el ser, a los entes y a las cosas; de la racionalidad científica y 
tecnológica con la que ha sido dominada la naturaleza y economizado el mundo moderno; de las relaciones e interdependencias entre estos procesos materiales y simbólicos, naturales y tecnológicos. La racionalidad ambiental que nace de esta crisis abre una nueva comprensión del mundo: incorpora el límite de lo real, la incompletitud del ser y la imposible totalización del conocimiento. El saber ambiental que emerge del campo de externalidad de las ciencias, asume la incertidumbre, el caos y el riesgo, como efecto de la aplicación del conocimiento que pretendía anularlos, y como condición intrínseca del ser. (2006, pp. 2-3)

Por su parte, Trevisan (1995); citado por Bergson (1999) plantea que sólo la intuición permite al ser humano alcanzar la duración o movimiento, la sustancia, la esencia y la existencia de las cosas. Se entiende como duración -en la filosofía bergsoniana- el volver-al-ser, el movimiento para el cambio, la producción de nuevas realidades. La inteligencia, de ninguna forma es capaz de alcanzarla, pues capta solamente lo material. Para Bergson (1999), el percibir es diseccionado por las representaciones que el ser humano ha acumulado en su experiencia, lo que a su vez ha sido profundamente influenciado por la memoria.

A su vez, Merleau-Ponty (1999) asegura que la percepción es independiente de cualquier tipo de configuración reflexiva. Es un movimiento de retornar al mundo que existe independiente del análisis que se pueda hacer de él, distinguiéndose por tanto del retorno idealista a la conciencia. Apoyándose en una base materialista, tal pensamiento distingue claramente lo imaginario de lo real perceptible, $y$ lo relaciona con la fantasía.

A ello se opone Castoriadis (1998), quien ve en el percibir y en el recordar una especie de imaginar: "Sería insuficiente decir que percibir supone imaginar. Percibir es imaginar, en el sentido literal y activo del término". Es en base a este concepto de percepción, aplicado al medio ambiente, que se persigue reflexionar sobre el lugar de lo imaginario y de las representaciones simbólicas de los grupos humanos en los estudios y prácticas de educación ambiental.

Para Cassirer (2001) la definición de los objetos, íntimamente ligada al mundo de las cosas existentes, carece del conocimiento de su naturaleza esencial, su patria espiritual. La realidad se ofrece a nuestros sentidos en su base material, pero al observarla se dirige a ella, repleto de apelaciones, es decir, de aquellas configuraciones que fueron agregadas a la identificación de la materia a lo largo de su historia en la interacción con el mundo. Coincidentemente, Eliade (1991) afirma que el hombre integral conoce otras situaciones, tan auténticas e importantes como su condición histórica, tales como el estado de sueño, de delirio, de melancolía y de contemplación estética.

Puede decirse entonces que los imaginarios corresponden a esa categoría de la conciencia que transita entre estos conceptos mencionados anteriormente y que los hace posibles como manifestación de la compleja superposición entre lo deseado y lo factible. Es una construcción más que subjetiva, intersubjetiva e intrasubjetiva que va más allá de la representación de las características denotativas del objeto o fenómeno, y que implica la apropiación de estas desde la historia de vida de quien le da el sentido. Por eso, el imaginario es más que la subjetivación de la imagen, puesto que esta se relaciona con la representación y aquella con el sentido otorgado a toda una vida de formas, sentimientos, percepciones, motivos para las acciones e interacciones, necesidades y deseos (Murcia, 2006). 
Retomando los términos acuñados por Cassirer (1971) al describir el modo en que los seres humanos construyen su imaginario, se puede agregar que ese proceso de pregnancia simbólica no se produce linealmente, sino que es un entramado complejo de relaciones de significado, significante, deseo y posibilidad. Pese a que el imaginario se expresa en lo simbólico, en el mundo de lo imaginario, lo simbólico es constituido y constituyente, pues se conforma a partir de la carga de sentido otorgada a la imagen y abiertos a nuevas disposiciones de significación. Por encima de las atribuciones a veces unidireccionales que les han dado a ambos, estos se resignifican entre sí permanentemente en la vida de los sujetos.

Peñuela y Álvarez (2002) aseveran además que lo simbólico articula nuevas posibilidades de representación y resignificación que recrean al sujeto y lo que él piensa en un proceso dinámico de atribución de significados y de significaciones compartidas, propiciándole posibilidades de existencia y mediación, lo que lo hace razonable. Al hablar de colectivos se refieren al lenguaje, pues es de esta forma en la que el sujeto se agrupa, modela organizaciones e instituciones que estructuran el orden social; además de ser lo común a un número de individuos; la característica de dicho grupo y su interés compartido; en otras palabras, se identifican en, y por algo. Entonces, los colectivos se articulan de formas diferentes en las posibles relaciones de su interacción en grupos, masas, redes, existiendo varios nombres para los mismos fenómenos.

Para Castoriadis (1998) los imaginarios sociales se forman en singulares matrices de sentido existencial como elementos coadyuvantes en la elaboración de sentidos subjetivos atribuidos al discurso, al pensamiento y a la acción social. Siempre son contextualizados pues responden a una historia que los caracteriza; no pueden verse como la suma de los individuales, sino el reconocimiento colectivo, de tal manera que "los imaginarios pasarían a ser sociales porque se producirían, en el marco de relaciones sociales, condiciones históricas y sociales favorables para que determinados imaginarios sean colectivizados, es decir instituidos socialmente» (Baeza, 2000, p.25).

Es evidente que su inserción depende de una creatividad asociada a cada situación específica; no obstante, se pueden los citar ejemplos que algunos autores manifiestan. Según Mari, Torres y Comar (2003, pp. 78-79), para Pruzzo (2002), la ciudadanía implica el desarrollo previo de la moral autónoma. «Él relata una experiencia positiva del uso de mitos, cuentos y leyendas para despertar reflexiones sobre las acciones humanas en diferentes culturas a lo largo del tiempo: "El mito actuó al mismo tiempo como detonante de la problematización y del surgimiento de preguntas, cuyas respuestas nos permitieron sumergirnos en las preconcepciones de los estudiantes" ». Las reflexiones despertadas son el punto de partida para la educación del sujeto político capaz de ejercer en la sociedad una ciudadanía responsable.

Abrantes (2002) trabajó con educadoras que realizaban su labor en favelas donde creó un espacio de discusión sobre la enseñanza entre los alumnos, ante quienes evidenció la necesidad de trabajar con imágenes propias de su espacio cotidiano captadas por los gestos, expresiones corporales y el discurso simbólico de los mismos.

Por su parte, un grupo de ambientalistas que trabajan con la reconstitución de parques y jardines a través de la participación popular, compuesto por investigadores de institutos de investigación de tres países europeos, lanzó el proyecto Paraísos - Paradise regained: New life for old gardens. Dicha participación es incentivada mediante actividades de sensibilización a partir del rescate de la imagen del paraíso y de propuestas contemplativas (Mazzoleni, 2002).

Estos ejemplos, que resultan antecedentes del trabajo de identificación e inserción de los imaginarios sociales en el ámbito educacional, permiten replantear el problema abordado en la introducción del presente artículo sobre cuáles son los imaginarios colectivos ambientales que presenta la comunidad 
educativa de la UTP y de qué forma estos pueden optimizar los alcances de la práctica pedagógica, en virtud de tributar con un referente teórico-práctico al momento de replicar la experiencia en diferentes sectores de la sociedad, tanto local como regional o nacional, para contribuir de esta manera al fortalecimiento de los alcances de toda acción que se desarrolle partiendo de los imaginarios colectivos en general.

\section{METODOLOGÍA}

Para alcanzar el objetivo trazado en la investigación se decidió seguir el enfoque de complementariedad etnográfica según Murcia y Jaramillo (2007), desde el cual se reconoce la complejidad de las realidades sociales y la necesidad del apoyo en diferentes teorías y métodos de recolección y procesamiento de la información, siempre que ayuden a la comprensión profunda de la realidad social estudiada. Estos autores explican que en la etapa de diseño e interpretación no se trata de yuxtaponer los datos cuantitativos y cualitativos, sino de articularlos en una interpretación que busque profundidad y amplitud. El dato, es un instrumento de información y al articularse con la sustantiva ayuda al propósito de comprensión de la realidad.

El diseño transita por dos momentos, en el primero se acude a la revisión documental y en el segundo, se aplica la encuesta técnica que permite indagar en la población estudiantil que transita por el campus universitario aspectos relacionados con sus imaginarios ambientales. Los dos acercamientos serán enriquecidos con elementos de análisis semántico, análisis de sentidos y análisis del contexto situacional, lo cual permitirá la construcción de categorías imaginarias ambientales, que paulatinamente configurarán un prototipo de imaginario ambiental. Para la aplicación de la encuesta, se tomó una muestra aleatoria simple, teniendo presente los estudiantes matriculados en los diferentes programas académicos; cada uno fue seleccionado de una muestra estadística representativa que tuvo en cuenta las características de la UTP; y así mismo se realizó el análisis de la recolección de datos.

La Universidad Tecnológica de Pereira - Colombia, es un escenario que abarca un campus de 36 hectáreas, en las cuales alberga 16217 estudiantes y 1200 docentes. Cuenta con 40 programas de formación técnica, tecnológica, profesional, especialización, maestría y doctorado. Para el logro del primer propósito de la investigación, se realizaron encuestas a estudiantes de los diferentes programas académicos que se encuentran registrados en ella.

En cuanto a la selección de los encuestados se tuvieron en cuenta los criterios: facultad, antigüedad en la institución, área de conocimiento. Los encuestados fueron elegidos bajo los requerimientos de un muestreo probabilístico aleatorio, en el cuál el universo es constituido por subgrupos de la población, en razón a lo cual el resultado muestral se define en la siguiente tabla:

Tabla 1. Tamaño de la muestra y su universo.

\begin{tabular}{l}
\hline Población/Universo \\
\hline No. de Estudiantes de pregrado: 16217 \\
No. de Estudiantes de postgrado: 1200 \\
TOTAL $\quad 17417$ \\
\hline
\end{tabular}

Fuente: Elaboración propia. 
Los datos fueron calculados bajo los siguientes parámetros:

$\checkmark$ Nivel de confianza: $95 \%$

$\checkmark$ Proporción de éxitos p: 0.5

$$
\mathrm{n}=\frac{Z^{2} p q N}{N E^{2}+Z^{2} p q}
$$

$\checkmark$ Porcentaje de error: $5 \%$

\section{Muestra $=\mathbf{3 7 6}$}

\section{RESULTADOS}

La siguiente información fue recopilada en la UTP durante el primer semestre del 2013 a través de una encuesta estructurada, realizada a diferentes miembros de la comunidad estudiantil, que permitió categorizar los significados otorgados a la palabra "ambiente". Los resultados se muestran en la siguiente figura:

Figura 1. Significados asociados a la lexía «ambiente».

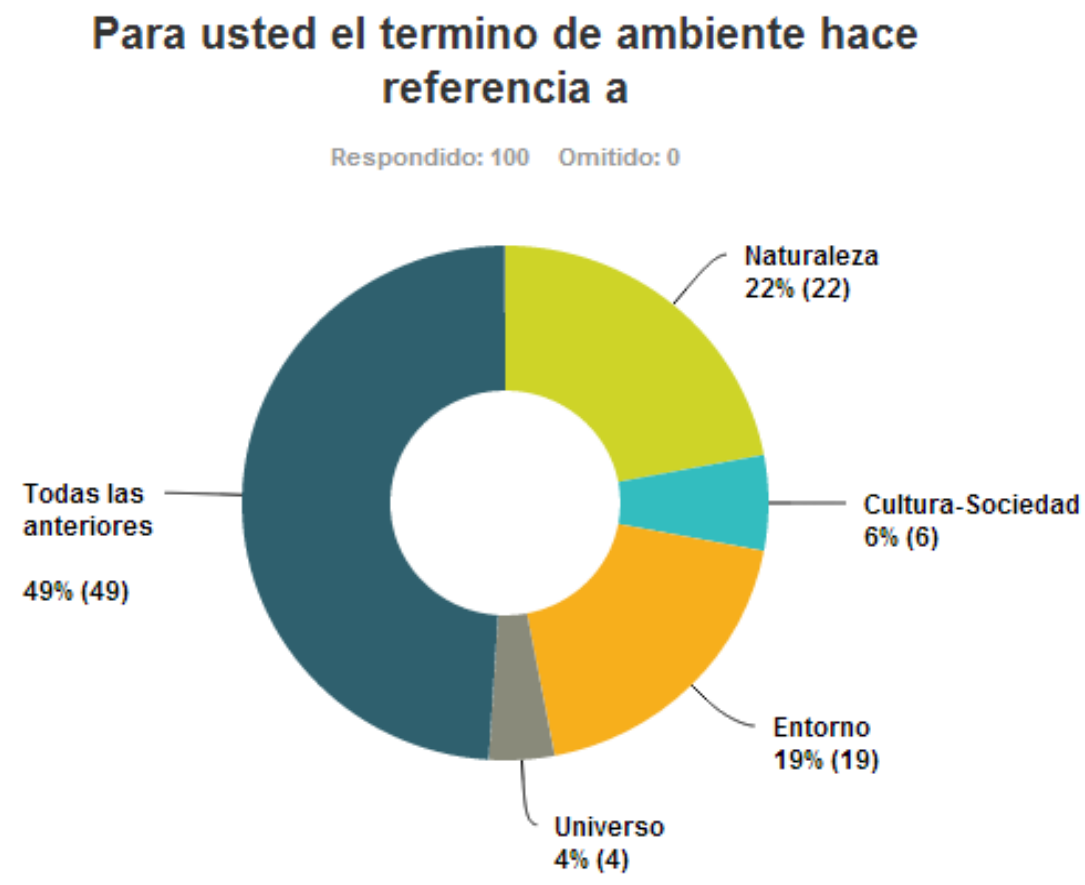

Fuente: Elaboración propia.

En la fifura se observa que el $49 \%$ de la población indagada asocian el término con todos los ítems presentados para la selección. El $22 \%$ de la población lo vinculan a aspectos naturales y en bajos porcentajes, los encuestados lo asocian con aspectos socioculturales. Tales respuestas evidencian el amplio espectro imaginario que la comunidad académica de la UTP posee frente al concepto; lo que marca una pauta propósito del que hacer académico para la construcción de un imaginario colectivo básico y fundamental.

Sobre cuáles son los mecanismos a través de los cuales los encuestados se han familiarizado con temas medio ambientales, el instrumento recogió que un $51 \%$ de la muestra manifiesta que ha obtenido sus conocimientos a través de los programas curriculares que brindan los diferentes programas académicos; sin embargo,un $21 \%$ aduce que son los medios de comunicación quienes le han permitido 
acceder a ellos, mientras que un $20 \%$ sostiene que fue por motivo de un interés particular. Asi se expresa graficamente:

Figura 2. Vías de aprehensión de conocimientos sobre medio ambiente.

\section{¿A través de que mecanismo ha conocido temas sobre medio ambiente?}

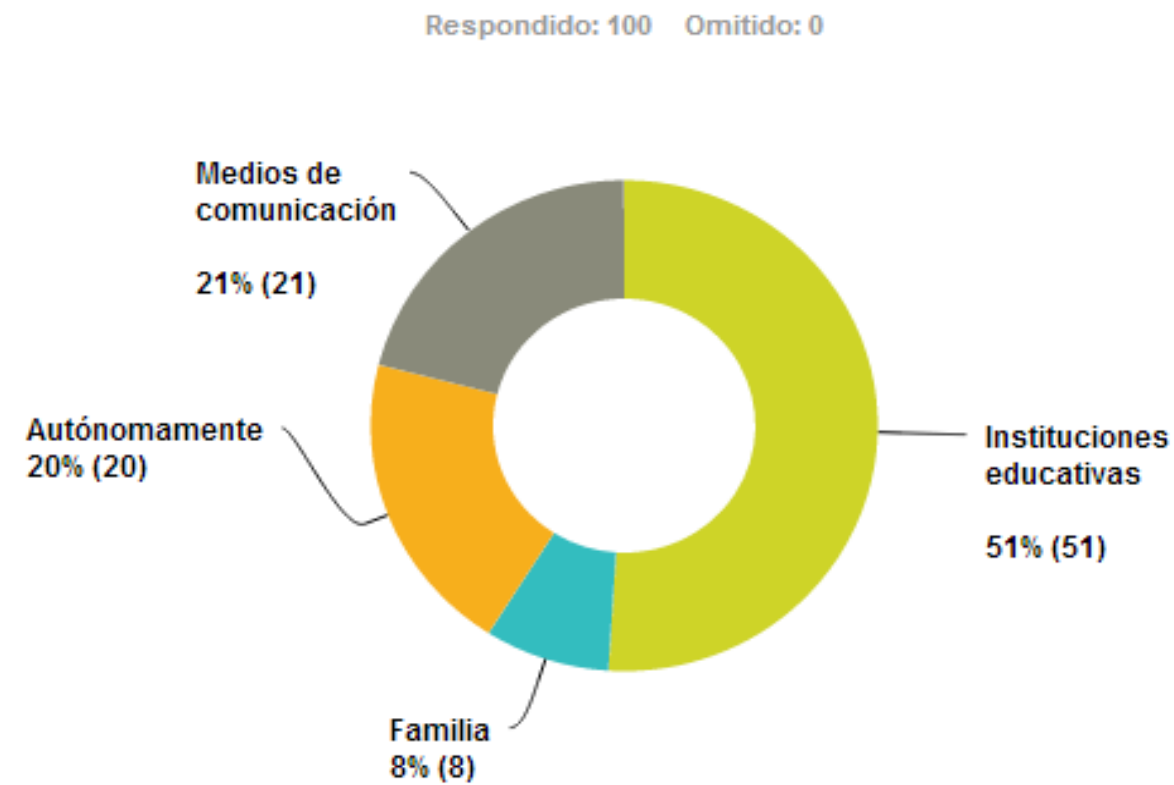

Fuente: Elaboración propia.

De acuerdo con la información representada en la Figura 3, el mayor porcentaje de la población, o sea, el $52 \%$ ha utilizado el jardín botánico de la universidad como espacio de formación,reflexión y apropiación de temas ambientales; sin embargo, es importante resaltar que el $27 \%$ sostieneno haber asistido a ningún espacio de formación en el cual se aborde esta temática. En menor porcentaje, la población consultada sostienen que las cátedras ambientales (promovidas por el instituto de investigaciones), los grupos de investigación y algunos seminarios son los medios que le han suscitado reflexiones medio ambientales. De lo que se puede concluir que el jardin botánico de la UTP posee un gran potencial como aula viva, que posibilita complementar los desarrollos teóricos abordados en los microcurrículos de los diferentes programas académicos. 
Figura 3. Espacios que promueven la reflexión sobre el medio ambiente.

\section{¿A qué espacios de reflexión y apropiación de temas ambientales en la universidad ha asistido? \\ Respondido: 100 Omitido: 0}

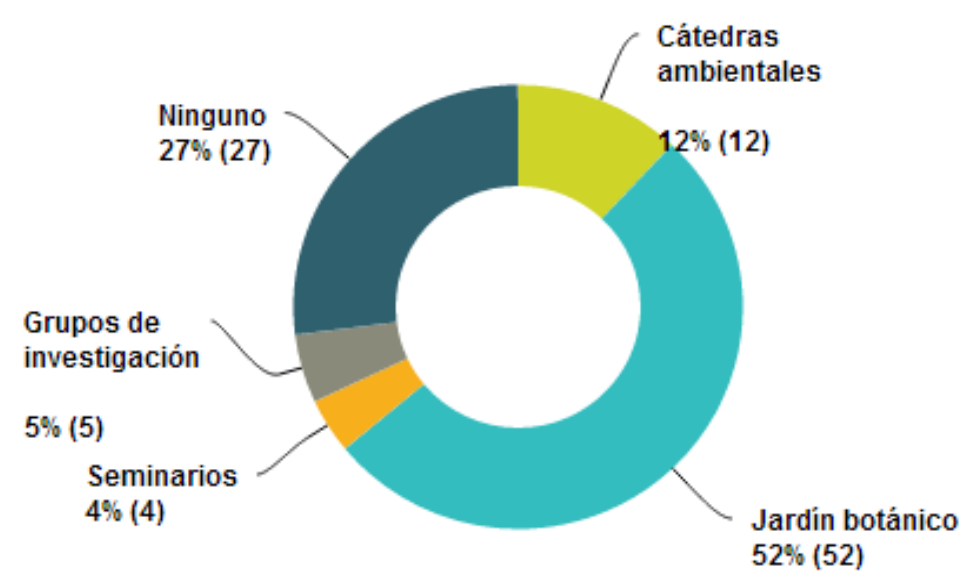

Fuente: Elaboración propia.

La Figura 4 recoge que para el $74 \%$ de la población encuestada es pertinente incluir los temas relacionados con la educación ambiental en sus procesos de formación profesional, con el fin de generar conciencia a propósito de la conservación de los recursos naturales.

Figura 4. Pertinencia de los temas ambientales en la formación del profesional.

\section{¿Por qué considera conveniente la inclusión de educación ambiental dentro de su proceso formativo?}

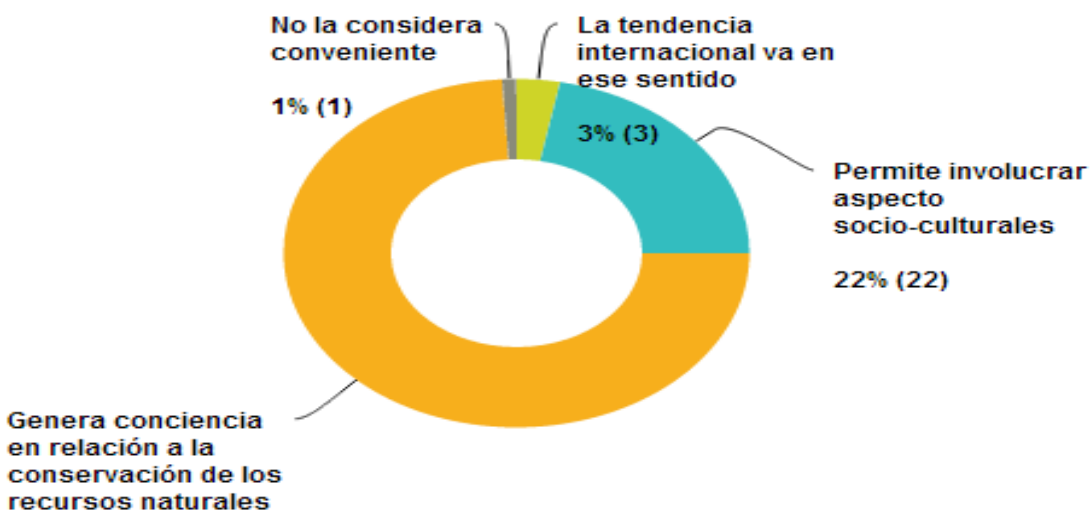

Fuente: Elaboración propia. 
De igual manera, un $22 \%$ de la comunidad indagada hace referencia a la importancia de incluir aspectos socioculturales como elementos articuladores en temas educativo-ambientales, de lo cual se puede hacer una estimación cualitativa del nivel de conocimiento que tiene una parte de la población al relacionar conceptos como sociedad, cultura y medio ambiente.

En la educación ambiental es un proceso permanente de carácter interdisciplinario destinado a la formación de una ciudadanía que forme valores, aclare conceptos y desarrolle las habilidades y las actitudes necesarias para una convivencia armónica entre los seres humanos, su cultura y su medio biofísico circundante (Ministerio Secretaría General de la Presidencia, 2011). Ésta debe ser entendida como el proceso educativo, en sus diversos niveles, a través de la transmisión de conocimientos y de la enseñanza de conceptos modernos de protección ambiental, orientados a la comprensión y toma de conciencia de los problemas ambientales, debiendo incorporar la integración de valores y el desarrollo de hábitos y conductas que tiendan a prevenirlos y resolverlos (Grupo Energético GEN, s.f.).

Desde esta perspectiva, se hace indispensable analizar los currículos de los programas académicos y generar reflexiones conceptuales, respecto a la necesidad de incluir el tema de la educación ambiental como eje transversal e integrador en la formación responsable y comprometida de los profesionales.

La figura siguiente evidencia que el $78 \%$ de la población tiene una marcada tendencia por comprender como recursos naturales, los bienes y servicios ambientales que se renuevan por ciclos naturales y se pueden agotar; en menor porcentaje se aprecia que la comunidad educativa los asocia con aquellos que son utilizados para beneficio propio o que tienen un valor económico.

Figura 5. Significados asociados a los recursos naturales.

\section{¿Qué entiende usted por recursos naturales?}

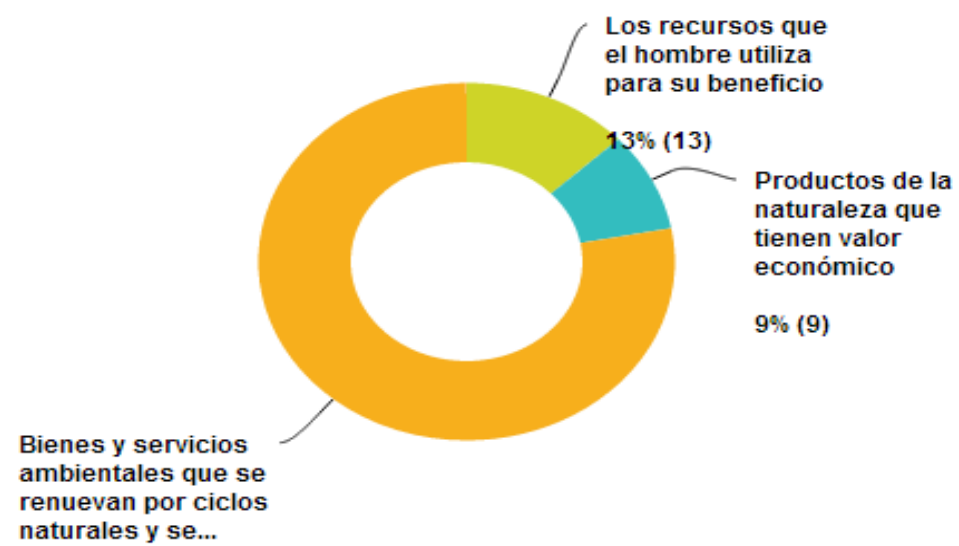

Fuente: Elaboración propia.

El $44 \%$ de la población opina que desarrollo sostenible es equilibrio dinámico entre las formas de desarrollo económico y ambiental; el $32 \%$ considera que es el uso de los recursos naturales de manera racional. Para implicaciones conceptuales y pedagógicas, se tiene que el $11 \%$ considera la opción de respuesta: desarrollo que no tiene en cuenta el efecto en el medio ambiente del crecimiento económico; solo el $3 \%$ de la población no tiene claridad sobre el término. 
Figura 6. Significados asociados al concepto de "desarrollo sostenible".

\section{¿Qué entiende por desarrollo sostenible?}

Respondido: 100 Omitido: 0

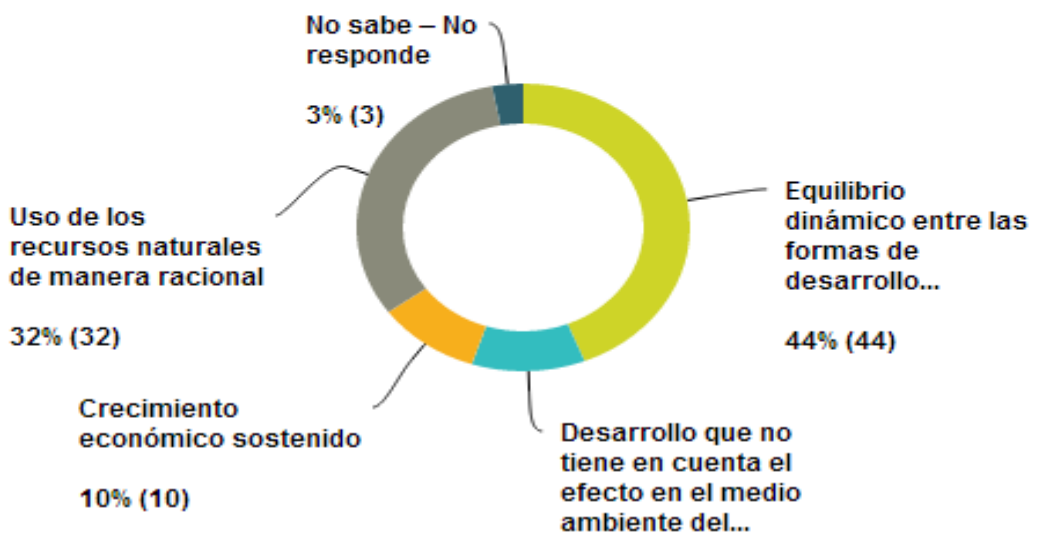

Fuente: Elaboración propia.

En este sentido, la Organización de Naciones Unidas (1987, p. 59) en el Informe Brundtland definió como desarrollo sostenible a aquel que «(...) asegura las necesidades del presente sin comprometer la capacidad de las futuras generaciones para enfrentarse a sus propias necesidades». Por ello se hace impresindible que desde la academia se incluya el análisis conceptualde estos postulados, con el fin de comprender las implicaciones individuales y colectivas que demanda el desarrollo en términos de calidad de vida.

Figura 7. Significados asociados a la gestión ambiental.

\section{¿Qué entiende por gestión ambiental?}

Respondido: 100 Omitido: 0

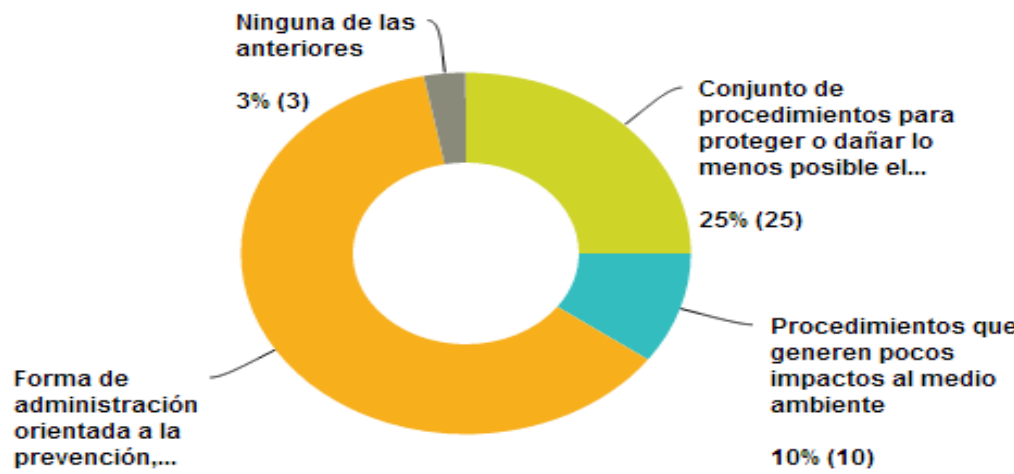

Fuente: Elaboración propia.

Como se muestra en la Figura 7, el $62 \%$ considera que la gestión ambiental es una forma de administración orientada a la prevención, reducción y minimización del impacto ambiental generado por las actividades antrópicas. Asimismo, el $25 \%$ de la población considera que se deben implementar 
procedimientos relacionados con la protección ambiental para minimizar los impactos negativos, mientras que el $3 \%$ no tiene claridad sobre el término.

Por otro lado, el $60 \%$ de la población consultada consideran que el impacto ambiental es la alteración de los componentes físicos, químicosy biológicosdel entorno natural.El 19\% dice que es un daño generado al ambiente; el $13 \%$ que es una intervención antrópica sobre el ambiente, y el $2 \%$ considera que el impacto ambiental no guarda relación con los temas indagados. Así queda expresado gráficamente:

Figura 8. Significados asociados al impacto ambiental.

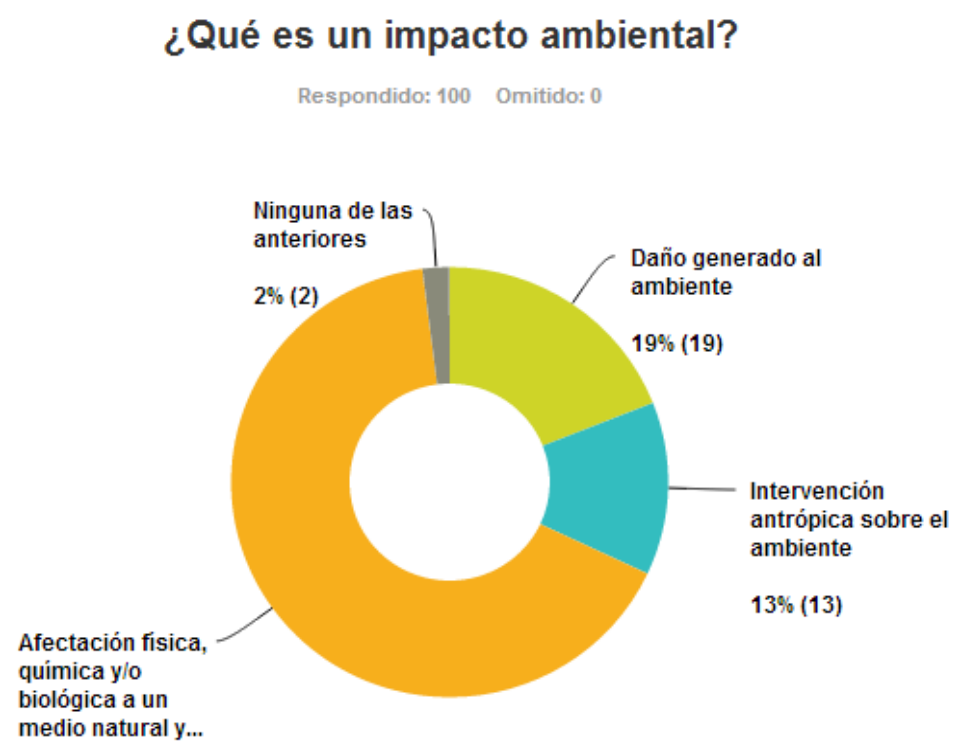

Fuente: Elaboración propia.

En base a las diferentes respuestas brindadas, se hace evidente que el tema del impacto ambiental simplemente se refleja en el daño que se hace al medio natural, por tal motivo resulta importante que desde la academia se planifiquen actividades formativas que conduzcan haciala reflexión individual de los modos de actuación del hombre, no solo en relación con el entorno, sino consigo mismo como individuo. 
Figura 9. Significados asociados a la problemática ambiental.

\section{¿Qué es una problemática ambiental?}

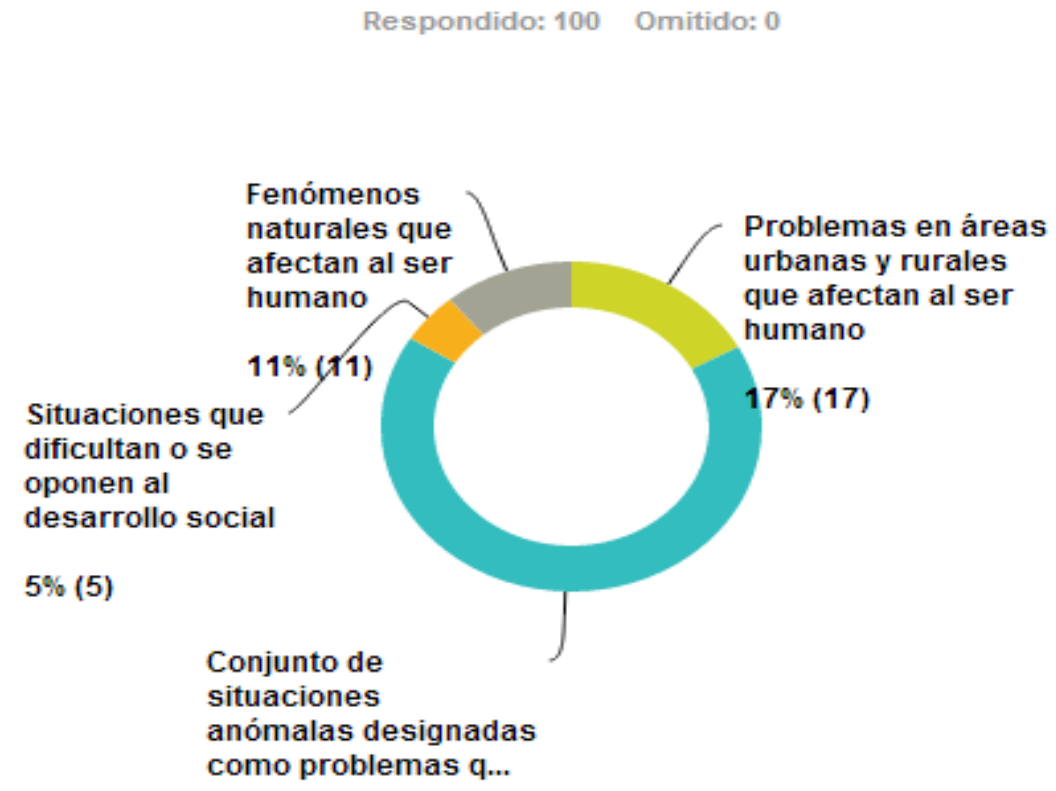

Fuente: Elaboración propia.

Según la gráfica anterior, el $67 \%$ de la población opina que una problemática ambiental es el conjunto de situaciones anómalas designadas como problemas que afectan el ambiente, y el $5 \%$ relaciona el concepto de desarrollo social con el de problema ambiental, eligiendo la opción de respuesta: situaciones que dificultan o se oponen al desarrollo social.

Una vez analizada la información recopilada, se evidencia que la comunidad académica de la UTP posee diversos imaginarios ambientales, no solo desde la conceptualización del término "ambiente», sino desde la comprensión misma de los problemas ambientales y sus alternativas de solución, entre otros.

Por consiguiente, una vez identificados los imaginarios ambientales que conviven en la institución, surge la necesidad de consolidar una propuesta pedagógica que atienda a su población académica y brinde las herramientas conceptuales mínimas para que, desde las diversas profesiones ofrecidas en el campus universitario, se tenga el imaginario ambiental acorde a la normatividad vigente en Colombia.

En este sentido, se aborda el uso de las Tecnologías de la Información y la Comunicación (TIC), pues estas generan nuevos ámbitos de motivación y pueden tributar al desarrollo de habilidades y competencias que contribuyan a mejorar las capacidades lectoras, analíticas y comprensivas de los estudiantes del campus. Así, el maestro, en el contexto de la cultura digital y de las emergentes ciberculturas, se dispone junto con los estudiantes a la creación de proyectos críticos y creativos, emprendimientos ciudadanos que viabilizan nuevos conocimientos y sensibilidades, nuevas formas de ser y de compartir mundos. 
Las herramientas pedagógicas disponibles e integradas al campus virtual para alcanzar dicho propósito son: Foros de discusión argumentada; el tertuliadero; la oficina virtual de RENATA ${ }^{1}$; el consultorio técnico; y el consultorio académico; si las mismas se articulan en cada aula virtual se transforma en el componente pedagógico con un enfoque constructivo de una asignatura electiva, ofertada a todos los estudiantes del campus universitario con el fin de informar y formar sobre los mínimos conceptuales del término "ambiente" $\mathrm{y}$ todas sus interrelaciones.

Ya en áreas como la Facultad de Ciencias Ambientales, en coordinación con UNIVIRTUAL ${ }^{2}$,se consolida un equipo de trabajo interdisciplinario en virtud de diseñar una propuesta académica que aborde aspectos conceptuales frente a temas como: ambiente, desarrollo sustentable, ciencia y tecnología, consumo responsable y producción limpia, entre otros.

Resulta válido puntualizar que UNIVIRTUAL realiza la actividad de construcción bajo el modelo del diseño instruccional, también conocido como diseño de instrucción, instructivo o educativo. Es una disciplina que vincula la teoría del aprendizaje con la práctica educativa y se interesa en la comprensión y mejoramiento del proceso de enseñanza y aprendizaje. Según Reigeluth (2002), citado por Tobón (2007) es una teoría que ofrece una guía explícita sobre cómo enseñar a aprender y mejorar. Está orientada a la práctica, centrándose en los medios para conseguir unos objetivos de aprendizaje y de desarrollo predeterminados; identifica métodos educativos - modos de favorecer y facilitar el aprendizaje- así como situaciones en las que dichos métodos deberán utilizarse o no deberían hacerlo. Facilita fraccionarlos en componentes más detallados que proporcionan a los educadores mejor orientación; además de ser probabilísticos más que deterministas, lo que significa que aumentan las oportunidades de conseguir los objetivos en lugar de asegurar la consecución de los mismos.

Ahora bien, es necesario precisar que el diseño instruccional se concibe como un proceso sistémico, dialéctico, creativo y flexible, que tiene un interés de establecer un puente entre las teorías del aprendizaje y la práctica educativa, al construir un sistema instruccional cuyas múltiples fases y componentes de planificación se abordan y se trabajan simultáneamente, en estrecha interrelación, más que de manera lineal, para la selección adecuada de los medios y estrategias de enseñanza, que permitan la construcción y reelaboración de aprendizajes significativos por parte de los alumnos, en función de los tipos de conocimientos que deberán aprenderse y las competencias que deberán desarrollarse o las metas o propósitos del proceso educativo.

Dentro de este modelo instruccional que se presenta y para ser consecuentes con los aspectos tanto pedagógicos como comunicativos presentados, se concibe el aprendizaje como un proceso activo de socio-construcción de significados por parte de los estudiantes, a través de la participación conjunta entre iguales, enfatizando el trabajo colaborativo mediante experiencias socioculturales y colectivas relevantes enfocadas en tareas auténticas, lo más cercanas posibles a su experiencia de vida o ámbito de actuación profesional.

De esta manera se crea la cátedra virtual denominada Producción y Consumo Sustentables, la que se estructura por medio de módulos de formación que abordan la siguiente temática:

- Módulo I Desarrollo sustentable: lineamientos básicos.

a. Modelo global y desarrollo sustentable.

b. La explosión del consumo.

c. La necesidad como dependencia y como potencial.

\footnotetext{
${ }^{1}$ RENATA es la red de tecnología avanzada que conecta, comunica y propicia la colaboración entre la comunidad académica y científica de Colombia con la comunidad académica internacional y los centros de investigación más desarrollados del mundo. ${ }^{2} \mathrm{La}$ incorporación de las TIC en la Universidad Tecnológica de Pereira a partir de Univirtual.
} 
d. Contexto de la Política Ambiental colombiana.

- Módulo II Consumo sustentable, mejor con menos.

a. Implicaciones ecológicas y socioculturales del modelo consumista.

b. Introducción al consumo sustentable.

c. Llevemos a la práctica el concepto.

- Módulo III Producción sustentable: el enfoque de producción más limpia como nuevo paradigma del desarrollo.

a. Conceptos PML: ¿Qué es y cómo convencer para empezar?

b. Revisión ambiental inicial y Análisis de ciclo de vida... ¿Cómo estamos?

c. Selección de soluciones PML: ¿Qué podemos hacer?

- $\quad$ Módulo IV Trabajo integrador.

Cada módulo posee una estructuración particular en la cual se presentan sus objetivos, lecciones, temas y actividades prácticas; los estudiantes pueden interactuar, retroalimentar la información, presentar sus puntos de vista y sobre todo, realizar actividades prácticas no solo en los lugares de trabajo, sino en sus propias casa. El link es http://univirtual.utp.edu.co/portal/scripts/inicio/index.php

Una vez consolidada, se presentó ante el Consejo de facultad, quien la aprueba en primera instancia con el fin de incluirla como asignatura electiva en décimo semestre para los estudiantes del programa de Administración del Medio Ambiente. Transcurrida esta fase, se llevó al Consejo académico de la UTP con el ánimo de poder brindarla como asignatura electiva en todos los programas que al interior del campus universitario se tienen. Es así como en 2013 se logró su generalización.

Como se aprecia en la figura siguiente, hasta la fecha la cátedra ambiental Producción y consumo sustentables registra 2284 estudiantes matriculados. También evidencia la dinámica en relación con el número de estudiantes por programa que toma en la actualidad el curso.

Figura 10. Estudiantes matriculados y programas a los que pertenecen.

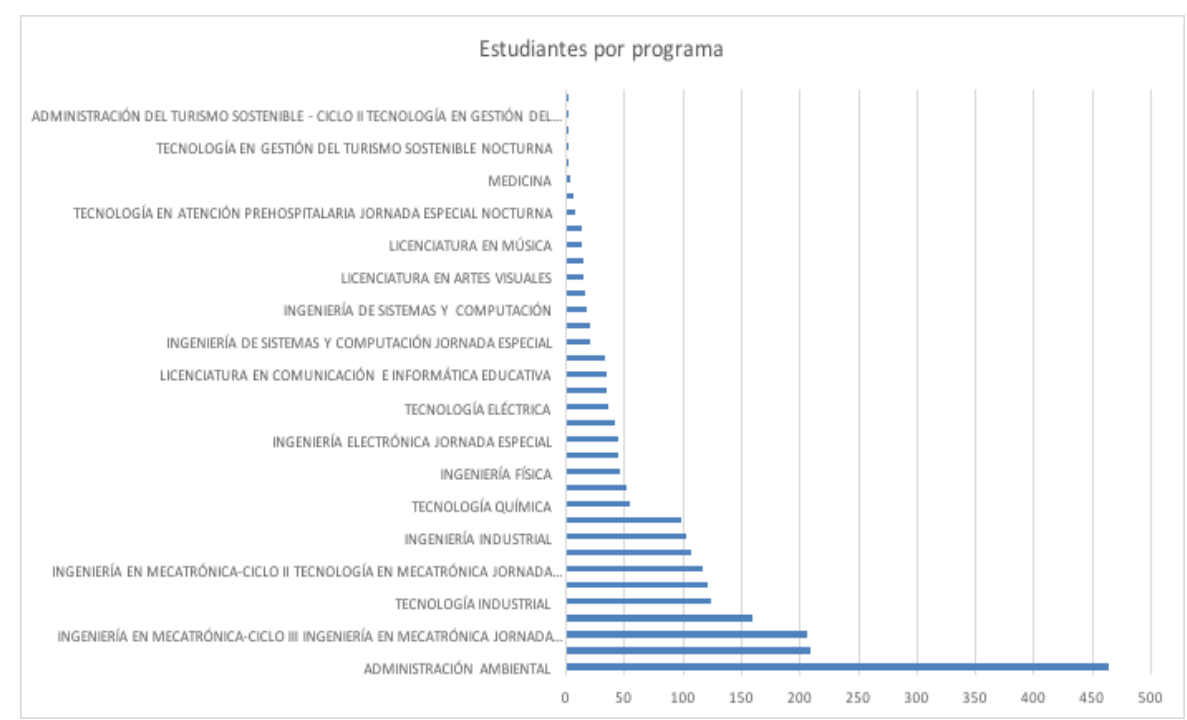

Fuente: Elaboración propia. 
Igualmente, se muestra a continuación el número ascendente de estudiantes por semestre desde el momento de su ofrecimiento inicial en 2013, primer semestre.

Figura 11. Estudiantes matriculados por semestre desde el 2013.

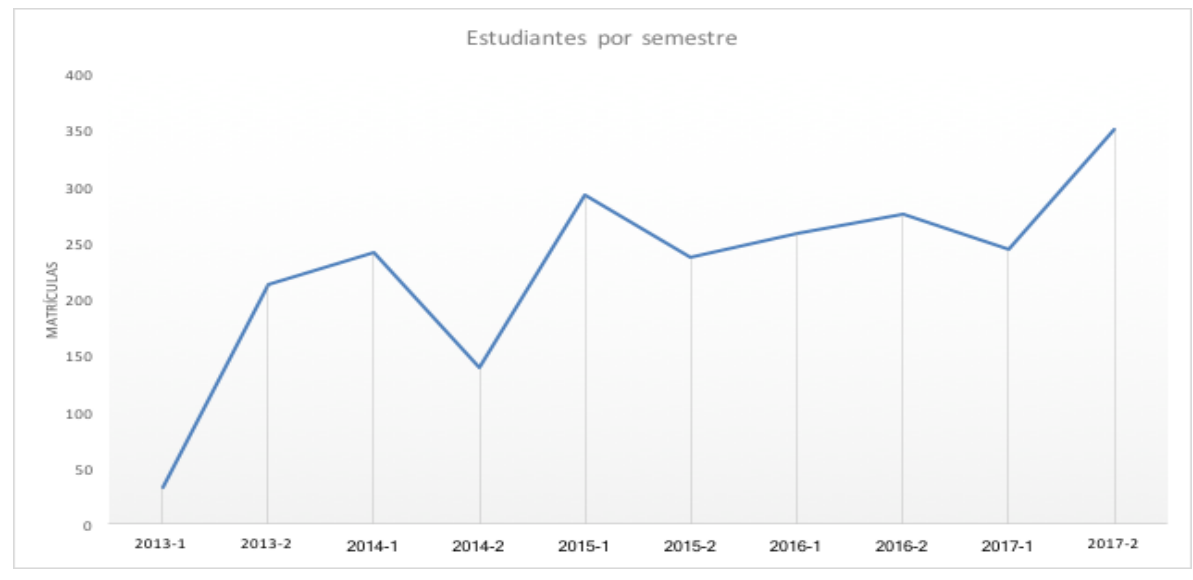

Fuente: Elaboración propia.

A raíz de estos resultados, la Facultad de Ciencias Ambientales presenta la cátedra virtual al Ministerio de Ambiente y Desarrollo Sostenible de Colombia con el fin de articular esta propuesta con la cátedra ambiental "Luis Eduardo Mora Osejo», y así involucrar a actores del Sistema de Información Nacional Ambiental (SINA) y la comunidad académica que forman parte de la Red Colombiana de Formación Ambiental (RCFA).

En la figura se aprecia el consolidado del convenio interadministrativo que permite llevar la cátedra virtual a diferentes lugares del país.

Figura 12. Alcance territorial por Convenio interadministrativo.

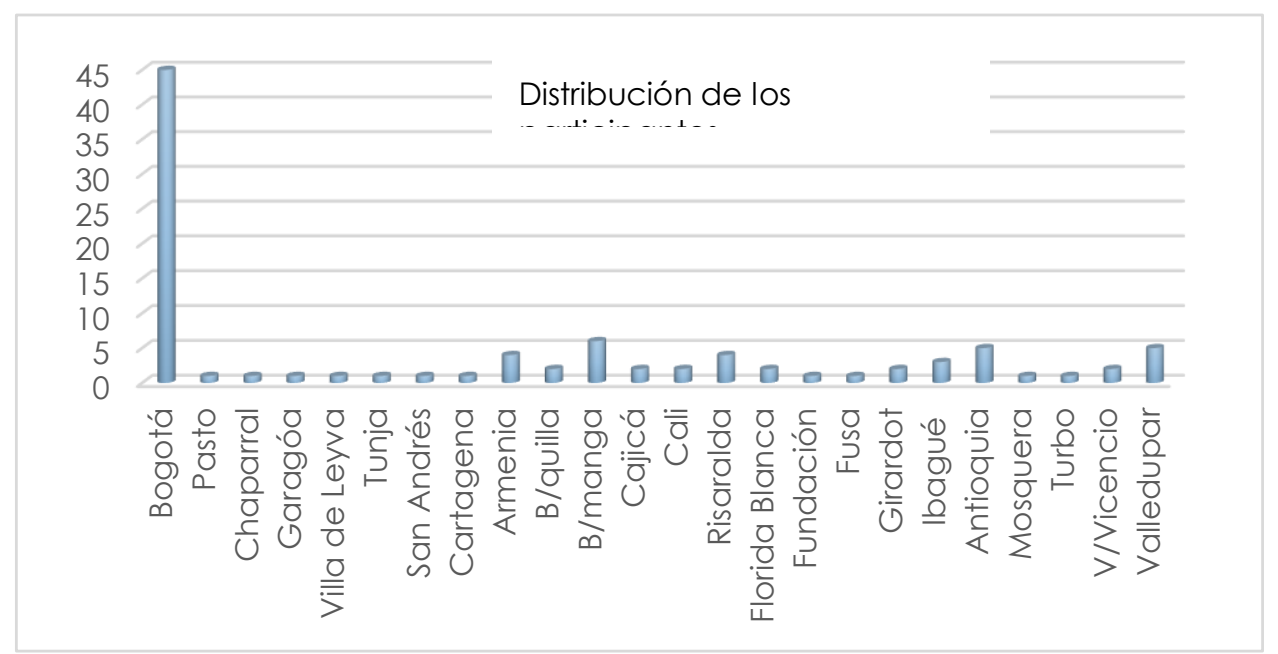

Fuente: Elaboración propia. 


\section{CONCLUSIONES}

La mayoría de los encuestados (49\%) definen el ambiente como la interacción conjunta entre los diferentes sistemas (naturaleza, cultura, entorno, tecnología y universo), por lo que se puede apreciar que se tiene un buen concepto sobre dicho tema. No obstante, otro porcentaje representativo es del $22 \%$, el que contempla al ambiente como naturaleza, entendiendo que todavía se encuentran vacíos sobre el asunto.

Se identificaron tres fuentes de conocimiento importantes de las que se sirve la población para instruirse en la temática: instituciones educativas (51\%), medios de comunicación (21\%) y autónomamente (20\%).

Del total de la muestra seleccionada, el $75 \%$ ha participado directamente en los diferentes espacios de la UTP con el fin de formarse en temas ambientales. Aunque lo anterior es un dato positivo, se presenta un $27 \%$ que no ha participado en ninguno de ellos por falta de comunicación o desinterés. Del mismo modo se refleja inasistencia a espacios tan importantes como lo son: seminarios, grupos de investigación y cátedras ambientales.

Un 78\% de los estudiantes encuestados tienen un concepto claro de lo que significa el término recursos naturales y lo identifican como bienes y servicios ambientales que se renuevan por ciclos naturales y se pueden agotar, lo que refleja un "progreso» en la conciencia colectiva frente papel que juegan los individuos humanos como agentes activos dentro del ambiente.

La población entiende por desarrollo sostenible el equilibrio dinámico entre las formas de desarrollo económico ambiental; o como el uso de los recursos naturales de manera racional, lo cual se encuentra acorde con la expectativa y las estimaciones conceptuales de dicho conocimiento. Igualmente sucede con el concepto de gestión ambiental, impacto ambiental y problemática ambiental, de los cuales la percepción colectiva está comprendida dentro de un marco conceptual adecuado en términos de educación ambiental.

Aunque la mayoría de los encuestados presenta una comprensión apreciable con la expectativa y estimación desde la educación ambiental (ambiente, recursos naturales, desarrollo sostenible, gestión ambiental, impacto ambiental y problemática ambiental), algunas personas todavía tienen vacíos relevantes sobre dichas temáticas; por lo tanto se debería considerar conveniente la inclusión de esta en los diferentes procesos formativos, así como la implementación de una cátedra ambiental específica enfocada a cada contexto académico y profesional.

Aunque la población de estudio cuenta con un nivel de conciencia y apropiación de los diferentes temas ambientales, sigue siendo necesario aunar esfuerzos que fortalezcan más el proceso pedagógico y cultural de la educación ambiental dentro de la universidad, con el propósito de alcanzar una masa crítica que permita obtener resultados evidentes y más contundentes en términos de acogimiento y respuesta social desde un contexto inmediato y con mayor trasfondo.

Sería de gran ayuda que las instituciones educativas, en este caso la Universidad Tecnológica de Pereira, entes gubernamentales y no gubernamentales, entidades públicas y privadas, y medios de comunicación, incluyeran con mayor fuerza el componente ambiental como parte de su gestión, permitiendo viabilizar en el futuro más investigaciones que aporten nuevas alternativas de desarrollo, mejoramiento y sostenibilidad para el país. 
Al observar la baja presencia en los seminarios, grupos de investigación y cátedras ambientales, es recomendable mayor incentivación, motivación y divulgación por parte de todo el sistema educativo dentro de la universidad, con el fin de generar una significativa participación en estos espacios.

Asimismo, se recomienda realizar capacitaciones sobre la temática que aborda cada grupo de investigación y semilleros, su alcance, objetivos, expectativas y logros, a través de la articulación entre grupos interinstitucionales con el fin de construir nuevas alternativas interdisciplinares.

\section{REFERENCIAS BIBLIOGRÁFICAS}

Abrantes, W. M. (2002). A pedagogia do gesto, do corpo, da simbologia em imagens. Igualdade $e$ diversidade na educación - XI Encontro Nacional de Didática e Prática de Ensino (XI ENDIPE). Universidade Federal de Goiás - Goiânia, Brasil.

Baeza, M. A. (2000). Los caminos invisibles de la realidad social: ensayo de sociología profunda sobre los imaginarios sociales. Sociedad Hoy.

Bergson, H. (1999). Matéria y memória. (M. Fontes, Trad.). São Paulo, Brasil.

Cassirer, E. (1971). Filosofía de las formas simbólicas, I: el lenguaje. Fondo de cultura económica.

Cassirer, E. (2001). Antropología filosófica, introducción a una filosofía de la cultura. Fondo de la Cultura Económica.

Castoriadis, C. (1998). Imaginación, imaginario, reflexión. Hecho y por hacer. Eudeba.

Eliade, M. (1991). Images and Symbols: Studies in Religious Symbolism. Princeton University Press.

Grupo Energético GEN. (s.f.). Educación Ambiental. Consultado el 10 de mayo de 2017. https://n9.cl/k47h

Lefft, E. (2006). La Complejidad Ambiental. Poli Revista Latinoamericana, 16(2007), 1-10. https://journals.openedition.org/polis/4605

Marin, A., Torres, H. y Comar, V. (2003). Percepción Ambiental, Imaginario y Prácticas Educativas. Tópicos en Educación Ambiental, 5(13), 73-80. https://dialnet.unirioja.es/ejemplar/453603

Mazzoleni, D. (2002). Paradise regained: new life for oldgardens. www.landscape.mmu.ac.uk/paradisos.

Merleau-Ponty, M. (1999). La prose du monde. Gallimard.

Ministerio Secretaría General de la Presidencia. (2011). Ley No. 19 300. Bases Generales del Medio Ambiente. Diario Oficial de la República de Chile. http://bcn.cl/1ux38

Murcia N. y Jaramillo L. G. (2007). La complementariedad etnográfica. Investigación Cualitativa. Una guía posible abordar estudios sociales. Kinesis.

Murcia, N. (2006). Vida Universitaria. Un estudio desde los imaginarios de profesores y estudiantes. [Tesis doctoral no publicada]. Universidad de Manizales

Organización de Naciones Unidas. (1987). Informe Brundtland. https://n9.cl/Ro3 
Peñuela, L. A. y Álvarez, L. G. (2002). Imaginarios Colectivos: implicaciones sociales. Una aproximación psicológica a las agendas de información. Razón y Palabra, 2002(26). http://www.razonypalabra.org.mx/anteriores/n26/lpenuela.html

Tobón, S. (2007). El enfoque complejo de las competencias y el diseño curricular por ciclos $\begin{array}{llll}\text { propedéuticos. } \quad \text { Acción 14-28. } & \text { Pedagógica, }\end{array}$ https://dialnet.unirioja.es/servlet/articulo?codigo $=2968540$ 